\section{La importancia del impulso a la investigación científica en la Sudamérica emergente}

\section{Sr. Editor.}

He leído con sumo placer y gratitud el artículo publicado en la Revista que Usted preside con DOI - http:// dx.doi.org/10.4321/S0376-78922019000100013 - “Tendencias y perfil de publicación de los cirujanos plásticos de los 22 países miembros de la FILACP, revisión de los últimos 20 años" de abril del 2019, publicado por el Doctor Alfonso Navia, Residente de Cirugía Plástica, en cuanto a la perspectiva de la investigación en Cirugía Plástica de los últimos veinte años de Ibero Latinoamérica; permítanme felicitarlos.

Me embarga un profundo placer el saber que la puerta de esta importante plataforma de comunicación científica en nuestra especialidad está abierta a los Residentes como autores, impulsores muchas veces y por qué no, gestores de muchos de los trabajos que se publican en esta prestigiosa plataforma y que, por políticas ajenas a nuestros propósitos, no figuran o pasan desapercibidos en los artículos presentados. Sumado a ello, se demuestra que las investigaciones observacionales pueden ser de gran impacto si se les da la dirección correcta, como considero este caso.

Según los reportes de Scopus Análisis y Scimago Research Group en cuanto a la evolución de la producción científica en general por regiones del mundo, Europa, EE.UU. y Asia lideran el ranking en producción. Pero lo interesante es que, en la última década, Latinoamérica está en franco crecimiento en comparación con los antes mencionados.

Bajo la misma fuente, en Latinoamérica el porcentaje de la producción local publicada en colaboración con instituciones de fuera del país está liderado por Chile y Colombia, llamando la atención que Brasil está en el séptimo lugar, debajo de México, mientras en la excelencia de estas publicaciones están a la cabeza Chile y Argentina. En esta oportunidad, Brasil se encuentra por debajo de Colombia y México en un quinto lugar; pero los autores brasileros lideran sobremanera la excelencia de publicaciones con una amplia preferencia por publicar en revistas extranjeras de países líderes.

Las investigaciones con publicaciones de impacto en estos países vienen fundamentalmente de universida- des, las cuales son las encargadas de formar de manera adecuada al Residente y brindar la fuente principal de pacientes, a quienes finalmente les debemos nuestro trabajo. España y Brasil tienen políticas públicas importantes en este ámbito, por lo cual los presupuestos para investigación científica son accesibles y generosos. En consecuencia, las universidades ganan prestigio. Ello se traduce en sostenibilidad y producción económica retroalimentable para la institución y para el estado que invierten en innovación y tecnología.

En nuestro caso en particular, en el Perú, soy optimista y vemos el vaso medio lleno; y me refiero al indicar que, este tipo de publicaciones en donde nuestro país aparece en estadísticas internacionales, así sea con 33 publicaciones en 20 años, son importantes para abrir puertas y fomentar las acciones necesarias que permitan aumentar las investigaciones e involucren tanto más aún al estado, universidades y entidades privadas para estos propósitos.

Es lógico pensar que la cantidad de cirujanos plásticos certificados en los países líderes en publicaciones supera sobremanera a los menos favorecidos, pero ello no es razón para desanimarnos y pensar que son pocas nuestras publicaciones. Vemos con beneplácito que en estos últimos años el Perú ha crecido en presencia en diversas plataformas, debido actualmente al interés por la investigación científica de los autores, al apoyo universitario y la necesidad de hacer de conocimiento público nuestros hallazgos.

Lo importante del estudio observacional y analítico de Navia y col. es que creemos, de acuerdo a la evidencia mostrada, que podría abrir más puertas para futuras acciones y políticas, tanto en lo privado como en lo público, para la puesta en marcha del propósito de $\mathrm{I}+\mathrm{C}+\mathrm{I}$ de los países sudamericanos en este inagotable y fascinante campo de acción, no solo en la reconstrucción y estética, sino también en la innovación, técnicas y contribución con tecnología, que creo es el gold standard en la sostenibilidad de la especialidad.

Finalmente esta publicación, por su contenido original, considero ha sido de sumo impacto, claro y preciso para los países miembros de la FILACP, y que al menos quienes escriben, la tomaremos en cuenta para impulsar políticas públicas y universitarias de apoyo a la investigación en Cirugía Plástica además de fomentar $\mathrm{I}+\mathrm{C}+\mathrm{I}$ en todo aspecto para seguir formando parte de esta gran familia que genera conocimiento al resto de lectores. Y 
considero también oportuno rendir homenaje a los Residentes de esta noble especialidad, que pese a sus labores arduas, se dan un tiempo para escribir a conciencia y poder así deleitarnos con sus lecturas, conocimientos e inquietudes, que se traducen en nuevas preguntas e hipótesis para el desarrollo de trabajos futuros.

Gracias por su atención.

http://dx.doi.org/10.4321/S0376-78922019000200015

Iván HERNÁNDEZ

Cirujano Plástico, INGECEL, Instituto Peruano de Ingeniería Celular y Manufactura Tisular e Instituto de Investigación en Ciencias Biomédicas, Universidad Ricardo Palma, Lima, Perú

\section{Respuesta a la carta del Dr. Iván Hernández}

\section{Sr. Editor.}

Recibo con sumo orgullo las palabras del Dr. Iván Hernández respecto a nuestro artículo. Sus felicitaciones son un fiel reflejo del buen camino que lleva nuestra comunidad Sudamericana desde el punto de vista científico y de la actitud optimista y de retroalimentación positiva que debe existir entre sus integrantes.

El análisis realizado por él es certero, más aún considerando que nos encontramos en una situación de desventaja real si tomamos en cuenta las estadísticas del Banco Mundial y la UNESCO, donde vemos que el porcentaje del PIB invertido en gastos en investigación y desarrollo a nivel global corresponde a un $0.8 \%$ para América Latina y el Caribe (rango 0.1-1.3\%) en comparación con un 2\% de la Unión Europea, 2.5\% de Asia Oriental y $2.7 \%$ de América del Norte, aproximadamente.

Es necesario que las autoridades que dirigen nuestras naciones tomen conciencia en que el futuro y el desarrollo van de la mano de fomentar y fortalecer políticas públicas en el ámbito de la investigación científica, especialmente hoy en día en que la tecnología avanza cada vez más rápido.

Aprovecho para felicitar también al Dr. Hernández y col. por lo interesante de sus publicaciones enfocadas en el área de terapias de regeneración tisular mediante el uso de fibrina autóloga, plasma rico en plaquetas y células madre, y publicadas en esta misma revista. ${ }^{(1-4)} \mathrm{Tal}$ cual se dio énfasis en el pasado congreso de la FILACP en Lima 2018, creo que esta última área junto a la optimización del uso, preservación y prendimiento de los injertos de grasa autólogos y la bioingeniería tisular, serán las temáticas que deberían liderar la producción científica internacional en los próximos años.
Por último, en una reciente encuesta realizada por nuestro grupo a 20 residentes de Cirugía Plástica de nuestro País de los últimos 3 años, un $64 \%$ cree que la falta de tiempo fue la principal razón por la cual no participó tanto como hubiese querido en trabajos científicos, seguido de un $21 \%$ que cree fue por falta de motivación y tutoría de parte de sus docentes. Por ende, es importante hacer nuevamente un llamado a los residentes de Cirugía Plástica internacional a inquietarse por la investigación, y a los docentes y entidades universitarias a prestar apoyo e incentivo a estas ideas y entusiasmo científico.

Nuevamente, muchas gracias.

http://dx.doi.org/10.4321/S0376-78922019000200016

\begin{abstract}
Alfonso NAVIA
Residente de Cirugía Plástica y Reconstructiva, Mg(c) en Investigación en Ciencias de la Salud, Sección de Cirugía Plástica y Reconstructiva, División de Cirugía, Pontificia Universidad Católica de Chile, Santiago, Chile.
\end{abstract}

\section{Bibliografía}

1. Rossani G., Hernández I. et al. Tratamiento de quemaduras mediante plasma rico en plaquetas (PRP): parte I. Cir. plást. iberolatinoam., 2014; 40(2): 229-238.

2. Hernández I. et al. Utilidad práctica de la fibrina autóloga en medicina reparadora y cirugía plástica. Cir. plást. iberolatinoam., 2014; 40(3): 345-357.

3. Hernández I., Rossani G., Castro-Sierra, R. Beneficios del adhesivo autólogo de fibrina y PRP en ritidectomía. Cir. plást. iberolatinoam., 2015; 41(3): 241-258.

4. Rossani G., Hernández I., Susanibar J. Inducción de crecimiento y restauración del folículo piloso con factores de crecimiento autólogos en patología no cicatricial del cuero cabelludo. Cir. plást. iberolatinoam., 2018; 44(2): 151-160. 